\title{
Assessing the Influence of Environmental and CEO Characteristics for Adoption of Information Technology in Organizations
}

\author{
Mumtaz Abdul Hameed', Steve Counsell ${ }^{2}$
}

\begin{abstract}
Information System literature has identified several factors that impact the adoption and implementation of IT. This study presents a meta-analysis of the findings of past literature on IT adoption to verify the significance of competitive pressure, government support, external pressure, CEO attitude, manager's tenure, CEO innovativeness and CEO IT knowledge in the adoption of IT in organizations. The study found that except for manager's tenure, all attributes had considerable influence on the adoption of IT. Amongst the factors considered, external pressure or the demands from the trading partners and potential customers were found to be most influential in the adoption process. The study also examined the effect of two moderating conditions for the relationship between the attributes and IT adoption.
\end{abstract}

Keywords: IT innovation adoption; meta-analysis; moderating effect.

' Department of Information Systems and Computing, Brunel University, Uxbridge, Middlesex UB8 3PH, UK. Email: Mumtaz.AbdulHameed@brunel.ac.uk

${ }^{2}$ Department of Information Systems and Computing, Brunel University, Uxbridge, Middlesex UB8 3PH, UK Email: Steve.Counsell@brunel.ac.uk 


\section{Introduction}

The study of innovation adoption began as early as 1940s, but the IS community only started focusing on diffusion of innovation research from the mid 1980s. The concept of innovation adoption has been studied in disciplines such as sociology, marketing, economics, communication, information systems, education and organizational management (Fichman and Carroll, 1999). Researchers and practitioners have made considerable efforts to gather knowledge in the innovation adoption phenomena and a large number of empirical studies have been carried out in the field of innovation adoption. Rogers (1995) defines adoption of innovation as the introduction of ideas, products, processes, systems and technologies regarded as novel to the adopting organization.

In the past two decades, research has focused on the notion of Information Technology (IT) adoption (Carter et al., 200I). Studies have examined various aspects of IT adoption at an individual and organizational level. Organizational level research centres on the adoption and diffusion with respect to the adopting organization (Lai and Guynes, 1997). Adoption of IT in an organization may influence performance and growth through improvement in productivity, competitiveness, efficiency and effectiveness.

Research has identified different factors that influence the adoption of IT in organization (Thong and Yap, 1995) and studies divide these factors into four major domains. They are the characteristics of the innovation, the features of the organization, the context of the environment in which it operates and finally, the perspective of individuals within the organization (in particular, the characteristics of CEO or business leader).

Despite the importance of IT adoption to organization, IT literature exhibits a knowledge gap in understanding and identifying the factors that influence the adoption process. With the large amount of literature that examines the different attributes that influence adoption process, a set of factors that either facilitates or hinders IT adoption has yet to be identified. Instead, variation in the empirical findings for different factors make its practical application ineffective; yet an understanding of the factors that determine the adoption of IT is fundamental for the success of any IT adoption process. The inconsistency in the findings of past research makes it almost impossible to draw a general conclusion on the effects of different factors that influence IT adoption.
This study herein aims to improve our knowledge of IT adoption in organizations. To achieve this, we attempt to identify the major determinants of IT adoption in terms of the characteristics of environment and CEO context. We reviewed past studies that examined environmental and CEO characteristics of IT adoption in organizations. We then used a meta-analysis technique to aggregate the results of their individual findings to identify its significance to IT adoption. The study examines different research conditions or 'moderators' that affect the relationship between characteristics of environment and CEO to IT adoption.

A better understanding of the major environmental and CEO characteristics that either facilitates or exhibits a successful IT adoption process is one of the contributions of this study. In addition, through past empirical studies, our findings contribute to determining the effect of different research conditions on the relationship between environmental and CEO attributes to IT adoption.

\section{Theoretical perspective}

\section{I Background of IT innovation adoption}

In the past two decades, understanding IT innovation adoption has become a key goal of both researchers and practitioners. The basis of IT innovation adoption research has been the link to Diffusion of Innovation (DOI), a theory introduced by Rogers (1983). DOI provides insights into the innovation or technological factors that influence the adoption of innovation. Originally, DOI was originally related to individual level adoption. However, integrating DOI with other models, researchers have been investigating innovation adoption in organizations. Besides technological factors, studies of innovation adoption in organizations have considered other dimensions within the organization that influences adoption of IT. For example, the Technology-Organization-Environment (TOE) framework suggested by Tornatzky and Fleischer (1990) identifies aspects of technology, organizational and environmental characteristics that influences organizational adoption of IT. Likewise, Kwon and Zmud (1987) identified five categories of factor as organizational, technological, environmental, task and individuals that can influence the adoption of IT in an organization. Thong (1999) in the study of information system adoption in small businesses identified variables of technology, organization, CEO and environment. 
An organization decides to adopt IT either to necessitate a demand from the environment in which it operates or a recognition from management that innovation is a requirement for their organizational functions. Hence, this study attempts to explore the environmental and CEO or business leader's characteristics that influence the adoption of IT.

\section{I.I Environmental characteristics studied in IT innovation adoption}

Organizations adopt innovation in reaction to an external demand or to achieve an advantage of an environmental opportunity (Damanpour and Schneider, 2006). The external environment plays a significant role in the adoption of new technologies and has been widely considered in IT innovation adoption in organizations.

Chwelos et al. (200I) in their Electronic Data Interchange (EDI) adoption model examined competitive pressure, external pressure, trading partner's support and trading partner's innovation readiness as environmental attributes. Quaddus and Hofmeyer (2007) considered competitive pressure, government support, trading partners support and vendor support as different environmental aspects in investigating the factors influencing adoption of business to business trading exchange in small businesses. Examining the adoption of four different IT innovations in US small businesses, Premkumar and Roberts (1999), considered competitive pressure, pressure from trading partners, trading partners support and vertical linkage in the context of environment. Grover and Goslar (1993) considered environmental uncertainty in the study of initiation, adoption and implementation of telecommunication technologies in US organizations.

\section{I.2 CEO characteristics studied in IT innovation adoption}

Research has also explored several CEO characteristics that influence the IT adoption process. Rogers (1983) suggests that innovation adoption is related to the innovation decision process. When the knowledge of the innovation is gathered, an attitude will be formed towards the innovation as to whether to adopt or reject innovation (Rogers, 1995). Top managers often make the final decision to adopt IT based on the internal needs of the organization or environmental changes (Damanpour and Schneider, 2006). CEO also takes the responsibility of managing and use technological innovation in organizations (Pinheiro, 2010). An organization's strategic decision to adopt or reject an innovation often reflects the personal characteristics of its top managers. Hence researchers have frequently examined various characteristics of CEO when addressing the factors influencing the adoption of IT in organizations.

In examining the CEO characteristics and organizational characteristics in IT adoption of small businesses, Thong and Yap (1995) considered CEO innovativeness, CEO attitude towards change and CEO IT knowledge amongst others. Damanpour and Schneider (2006) investigated manager age, gender, education level, tenure in position and attitude towards innovation while focusing on the organizational, environmental and top managers' effect on the phases of the adoption of innovations in organizations. Larsen (1993) studied the effect of middle managers' age, middle managers' tenure in position and middle managers' education or IT knowledge that contributed to implementing IT innovation in organizations.

\section{Research Methodology}

As the finding of an individual study is not adequate to generalize on a particular subject, researchers often combine the results of several studies to draw together a more comprehensive body of knowledge. Both quantitative and qualitative data can be aggregated in this way. The qualitative approach summarizes the conclusions of others in a narrative outline. However, a quantitative approach combines independent observations into an average measurement and draws overall conclusion regarding the magnitude and direction of the results (Ellis, 2010). Established methods have been developed to combine quantitative data from several studies. Researchers have used statistics such as 'test of significance' and other 'effect sizes' to combine the quantitative findings of individual studies.

The methodology used for the research presented was to combine quantitative findings of past literature on IT innovation adoption using statistical techniques. The study gathered empirical research that investigated the adoption of IT in organization. Furthermore, among these studies we extracted those that examined environmental and CEO characteristics. To aggregate and analyse the data extracted from the studies, a statistical method known as 'meta-analysis' was used. This was used to evaluate the strength and association of each of environment and CEO characteristic with IT adoption. 
We assessed the effect of different research conditions commonly known as 'moderators' on the relationship between environment and CEO characteristic with IT adoption. Such moderating conditions affect the strength, significance and direction of the relationship between individual attributes and IT adoption (Guzzo et al., 1987). We segregated the extracted data for each moderating condition and performed the meta-analysis to assess the effects of each of these circumstances.

\section{I Aspects of Quantitative Statistics from past studies}

'Test of significance' and various other 'effect sizes' provided by quantitative studies can be aggregated to find an overall outcome. The relationship between independent and dependent variables is usually evaluated in term of 'test of significance', highlighting their relationship. A significance test is validated if an observed value of a statistics deviates enough from a hypothesized value (null hypothesis). The result of a significance test only indicates the probability level.

The measure of effect size is the 'correlation coefficient' between the independent and the dependent variables (Cooper et al., 2009) and gives a measure of the strength and direction of relationship between two variables. Its value is a real number between $-I$ and $+I$. A correlation coefficient of $I$ suggests that the two variables are perfectly related and $-I$ indicates that the variables are inversely perfectly related. A correlation coefficient of zero specifies that two variables are unrelated.

Size of correlation coefficient when considered in terms of significance is frequently referred as weak, moderate or strong significance. However, there is no rule for determining the value of correlation that interprets as weak, moderate and strong. Cohen et al. (2007) interpret correlation co-efficient as: weak $(0- \pm 0.1)$, modest $( \pm 0.1$ - \pm 0.3$)$, moderate $( \pm 0.3- \pm 0.5)$, strong $( \pm 0.5- \pm 0.8)$ and very strong $( \pm 0.8- \pm I .0)$. As a rule, correlation coefficients less than 0.3 are considered weak, values between 0.3 and 0.7 moderate and greater than 0.7 considered strong. De Vaus (2002) modified the classification and referred to a correlation value between 0 and \pm 0.09 as insignificance, \pm 0.10 and \pm 0.29 as weak significance, \pm 0.30 and \pm 0.49 as moderate significance, \pm 0.5 and \pm 0.69 as strong significance, \pm 0.70 and \pm 0.89 as very strong significance and \pm 0.9 and \pm 1.0 near perfect.

\subsection{Aggregating studies}

The test of significance is determined by the combination of effect size and sample size of the study (Rosenthal and DiMatteo, 200I). This means that depending on the size of the sample, a relationship can be strong but insignificant and conversely weak, nevertheless significant. Hunter et al. (1982) suggest that aggregation of 'test of significance' from different studies could produce misleading conclusions.

A more precise statistical technique exploited to combine previous quantitative research finding is 'meta-analysis'. Meta-analysis gives the strength, significance and the direction of the relationship between independent and dependent variable. The basic principle of meta-analysis is to calculate the effect size of individual studies and then combine them to obtain an average effect size (Rosenthal and DiMatteo, 200I).

\subsection{Meta-analysis}

Meta-analysis is the use of statistical techniques for combining a set of similar studies for the goal of integrating their findings (Hunter et al., 1982). It is also a method for rigorously analyzing summative data in order to find a more accurate account of the relationship between two variables (Glass et al., 1981).

Meta-analysis describes a set of numerical procedures for systematically reviewing research, examining a particular effect and then combining the results of independent studies to derive an overall population estimate. One of the most commonly followed methods for metaanalysis estimation is that by Hunter et al. (1982) which corrects sampling errors, errors of measurement and range of variance. In a study based on meta-analysis of organizational characteristics influencing IT adoption, Damanpour (1991) followed the steps describe by Hunter et al. (1982); herein, we replicate the meta-analytical steps of Hunter et al. (1982). Ellis (2010) stated that 'meta-analysis offers a more objective, disciplined and transparent approach to assimilating extant findings than the traditional narrative review'. 


\subsection{Data Collection}

An exhaustive literature search was undertaken to find articles based on factors influencing IT adoption. Literature covered studies from 1990 to 2010. We searched all major IS and management Journals with the keywords: innovation; adoption; implementation, diffusion; infusion; integration; information technology, information system (IS) and IT usage. The search targeted studies which examined the environmental and CEO attributes of IT adoption. The dependent variable of the study was required to be initiation, adoption-decision or implementation of IT.

The study managed to gather a total of 39 studies that examined different environmental or CEO factors influencing the adoption of IT. As some studies considered more than one innovation or different stages of innovation adoption as dependent variable, a total of 52 innovation adoption relationships with IT adoption were used for our analysis. As the meta-analysis methods make use of a correlation coefficient, for the meta-analytic procedures we chose the study that performed correlation analysis for each of their relationships. Correlation results of 22 studies were used to perform the meta-analysis steps.

The Appendix shows individual studies considered for the study. It shows the sample size, the results of test of significance, correlation values for the relationship with IT adoption and other demographic statistics.

\subsection{Independent variables for the study}

To perform the meta-analysis procedure, at least two correlation results for relationships between individual factor and IT adoption were required. All factors that had more than two correlation results were considered for the analysis. Thus the study was able to consider 3 environmental and 4 CEO characteristics that influenced the adoption of IT. These 7 factors are the independent variables for the study with the dependent variable as Adoption (initiation, adoption-decision or implementation) of IT innovation.

Table I illustrates the factors considered and it's expected association with IT innovation adoption. A positive association 'enables' IT adoption and a negative association 'inhibits' IT adoption. The following sub-sections describe each of these factors.

\begin{tabular}{|llc|}
\hline Independent factors & \multicolumn{1}{c}{ Description } & Expected Association \\
\hline Competitive Pressure & The competition faced by the business in its particular industry & Positive \\
Government Support & The government initiatives and policies to promote IT adoption and use & Positive \\
External Pressure & Pressure from trading partners and customer to adopt a particular innovation & Positive \\
CEO A ttitude & CEO's positive perception of the adoption and implementation of IT & Positive \\
M anagers Tenure & The number year the manager is in the management position & Positive \\
CEO Innovativeness & CEO's enthusiasm in the adoption of new innovations & Positive \\
CEO IT K nowledge & CEO's basic knowledge of technological innovation & Positive
\end{tabular}

Table I. Environmental and CEO characteristics and its expected relationship to IT adoption 


\subsection{Competitive pressure}

Competitive pressure is the level of competition within the environment the organization operates. A successful business approach is to build a competitive advantage in the marketplace. It is generally believed that competition necessitates innovation adoption and increases the probability of adoption of IT (Kimberley and Evanisko, 198I). A number of studies have shown that competitive pressure influences the adoption of IT (Chwelos et al., 200I; Looi, 2005; Zhu et al., 2006b). Competitive pressure is generally perceived to have a positive influence on the adoption of IT (Gatignon and Robertson, 1989) and is one of the widely mentioned reasons for organizations to adopt IT.

The reviewed literature identified 27 competitive pressure-IT adoption relationships from 19 different studies. The meta-analysis procedure for competitive pressure considered 16 sets of IT adoption relationships from II different studies.

\subsubsection{Government support}

Government involvement plays an important role in promoting technological innovations in organizations (Lin, 2008). Government through regulations can encourage the adoption of innovation in organizations (Tornatzky and Fleischer, 1990). By implementing guidelines and providing financial assistance, policy makers can facilitate the adoption of IT in organizations. Government can encourage adoption IT in organizations by providing training, technical support; independent advice and other incentives. Several researchers in recent year have studied the role of government in the adoption of IT and it is generally agreed that government support has a positive relationship on adoption of IT (Jeon et al., 2006; Looi, 2005).

Among the studies reviewed, 9 studies empirically examined the relationship between government support and IT adoption. In these 9 studies, 13 innovation adoption relationships with government support were observed. To perform the meta-analysis on government support, a set of 7 IT adoption relationships from 5 studies were considered.

\subsubsection{External Pressure}

External pressure here refers to the influence from trading partners and customers. The pressure exercised by powerful trading partners to adopt an innovation influences the adoption decision of an organization (lacovou et al., 1995). An organization that adopts a particular innovation would demand their partners to possess a similar innovation process to fully utilise the innovation at an inter-organizational level. Similarly, the demands from potential customers to possess an innovation have a strong impact on the adoption of IT in organizations (Abereijo, 2009). Small businesses are very vulnerable to customer pressure, since they are more likely to be economically dependent on larger customers for their survival. The pressure from trading partners and customers is particularly high for small organization compared to larger businesses (lacovou et al., 1995). Studies have provided evidence that significant external pressure in the adoption of IT and hypothesized external pressure can have a positive relationship with IT adoption (Chan and Ngai, 2007; Chwelos et al., 200I; Teo et al., 2009).

External pressure was considered in 14 of our reviewed literature studies with 2 I IT adoption relationships. For the meta-analysis, 6 external pressure-IT adoption relationships were gathered from 4 studies which performed correlation analysis.

\subsubsection{CEO attitude}

The CEO's perception of new innovation plays an important role in the adoption of IT. CEO's innovativeness and favourable attitude of new technology affects in a positive way the adoption of IT (Damanpour, 1991). According to Rogers (1983), the creation of attitude towards an innovation happens before a decision to adopt has been made. Top management's favourable attitude assists all stages of IT adoption. In the initiation stage, managers' help developing awareness among the organizational members, in the adoption-decision stage they are responsible for allocating necessary resources and in the implementation stage they can create an environment for smooth integration into the organizational settings. Mehrtens et al. (200I) found a direct link between CEO's positive attitude towards adoption of IT and success of adoption process. Every adoption process is associated with uncertainty; however, a CEO with more positive attitude challenges these risks and continues to maintain their enthusiasm by committing increasing amounts of resources. 
We gathered 8 studies that examined CEO attitude with 10 sets of IT innovation relationships. Of these 8 studies, we used 5 studies with 7 IT innovation relationships for the meta-analysis to verify the association between CEO attitude and IT adoption.

\subsubsection{Manager's tenure}

Manager's tenure refers to the length of time the CEO has been in their current job. Researchers found contradictory results when examining manager's tenure. Experienced managers with their organizational 'know how' can facilitate a smooth adoption processes and at the same time use their authority to establish an atmosphere for a successful IT implementation (Kimberly and Evanisko, 198I). CEOs with longer tenure have a better knowledge of the organizational operations and would be more competent in handling unforeseen events that may arise due to the adoption IT. Hence, more experienced managers will be more advantageous for the adoption of more complex innovation (Damanpour and Schneider, 2009).

On the other hand, some researchers argue that top managers new to their position brings innovative ideas and are more open to change (Huber et al., 1993). In an empirical study Sharma and Rai (2003) found that organizations with a CEO on a shorter tenure had a higher adoption rate. The majority of studies that investigated manager's tenure verified a significant influence on IT adoption (Damanpour and Schneider, 2006). Hence, we predict a positive association for the relationship between manager's tenure and IT adoption.

In this study we drew together 4 studies that considered manager's tenure to examine the influence on innovation adoption. A total of 5 sets of correlation relationships were used to performed meta-analysis on manager's tenure with IT adoption.

\subsubsection{CEO innovativeness}

CEOs can influence IT adoption by virtue of their innovativeness and interest toward change. Due to the dominant role of CEO in small businesses, these aspects are essential in the adoption of IT. CEO willingness to innovate notably dictates the adoption of IT (Thong and Yap, 1995). Cragg and King (1993) discussed the role of CEO as a product champion. In small businesses, the CEO is usually the owner and the sole decision maker and CEO's innovativeness and involvement contributes to the success of any IT adoption process (Poon and Swatman, 1998). Innovative CEO's are willing to take risks and would prefer solutions that have not been tried before (Thong, 1999). Past literature found CEO innovativeness significantly and positively influenced the adoption of IT (Thong and Yap, 1995; Thong, 1999; Mirchandani and Motwani, 200I).

CEO innovativeness was considered in 6 of our reviewed studies with 7 IT innovation adoption relationships. For the meta-analysis, 4 CEO innovativeness-IT adoption relationships were used from 3 studies which presented correlation values.

\subsubsection{CEO IT knowledge}

Individual characteristics of CEO play an important role in the adoption and assimilation of IT in organizations. Amongst these CEOs, IT knowledge was found to have a strong correlation with IT innovation adoption (Thong and Yap, 1995; Jeon et al., 2006; Chan and Ngai, 2007). A CEO with more IT knowledge is able to assess the benefits of new technology and more likely to adopt innovation. Lack of IT knowledge creates uncertainty and it is only the awareness through knowledge that informs confidence in new innovation which facilitate adoption (Rogers, 1995). Gable and Raman (1992) found that CEOs in small organizations lack the basic knowledge of IT and have insufficient awareness of the potential benefits of IT adoption. CEOs with no IT knowledge are less likely to commit resources for IT adoption.

Out of 39 studies, 10 studies assessed CEO IT knowledge and IT adoption with 14 relationships. For the meta-analysis, I3 CEO IT knowledge-IT adoption relationships were gathered from 9 studies to perform the correlation analysis.

\subsection{Moderator conditions for the study}

The boundary condition with which the research was performed may affect the relationship between the CEO or environmental attributes and IT adoption. Through meta-analysis procedures, the effect of these conditions or moderators can be analysed further.

Based on the most commonly quoted demographic in the literature considered for this study, we selected two moderators. We name them stage of innovation and type of innovation, each of which is described in the next sub-sections. 


\subsection{Stage of Innovation}

Distinguishing stages are widely used in the IT adoption process. These stages are generally categorized as preadoption, adoption-decision and post-adoption in IS literature. However, Thompson (1965) describes the innovation process as a sequence progressing from initiation to adoption to implementation. Rogers (1995) classified into initiation, adoption-decision and implementation stages. Klein and Sorra (1996) divides four adoption phases stages with awareness, selection, adoption, implementation and routinization while Angle and Van de Ven (2000) refers to initiation, development, implementation and termination. Hage and Aiken (1970) describe the adoption process as propagating through awareness, selection, adoption, implementation and routinization stages. Zaltman et al. (1973) grouped into initiation, development, implementation and termination phases. Cooper and Zmud (1990) describe a six stage model of initiation, adoption, adaptation, acceptance, routization and infusion.

The set of stages illustrated by different research falls more or less into the pre-adoption, adoption-decision and post-adoption phases. Thompson's (1965) and Rogers' (1995) model of initiation, adoption-decision and implementation precisely addresses these three phases. This study therefore uses the three stage model of initiation, adoption-decision and implementation.

Rogers (1995) describes the activities of the initiation stage as recognizing the need for a new innovation, identifying an appropriate innovation and then proposing new technology for adoption. In the adoption-decision stage, the organization evaluates the proposed innovation to make a decision on its adoption and allocate necessary implementation resources (Meyer and Goes, 1988). The implementation stage involves putting the innovation into practice; getting user acceptance and making the innovation a routine feature in organizational operations (Rogers, 1995).

\subsubsection{Type of innovation}

Zmud (1982) classified type of innovation as product and process. Zaltman et al. (1984) distinguishes between radical innovation and incremental innovation. Likewise, Damanpour (1991) makes the distinction between product and process innovation and administrative against technical innovation. Gopalakrishnan and Damanour (1997) categorizes innovation as radical versus incremental, technical versus administrative and product versus process.

Radical innovation refers to the change of an entire system of operation whilst incremental to progressive enhancement of the existing practices and processes. Technical innovation implies the adoption of innovation that has an effect on productivity, whereas administrative innovation changes the institutional structure of an organization. Product innovation is the introduction of new product or services. Process innovation on the other hand is the introduction of a new system or method that changes the process of its working practice.

Studies have identified various adoption features for both product and process innovation (Utterback and Abernathy, 1975; Damanpour and Gopalakristnan, 200I). Variations in the adoption of product and process innovation mainly account for the activities of the effect of adoption (Gopalakrishnan and Damanpour, 1997). Product innovation introduces new products into the existing system to enhance services, whereas process innovation involves establishing a new system or method that changes the operational processes. Different factors determine the adoption of product and process innovation and extent to which these factors impact on the adoption process (Tornatzky and Fleischer, 1990).

\subsection{Meta analysis procedure}

In this study we applied the meta-analysis procedures describe by Hunter et al. (1982) and use values of the correlation coefficient to aggregate results of the studies. Adhering to procedures by Hunter et al. (1982), we performed the sequence of computations described below. First, we calculated the mean population correlation for the studies (MEAN CORRELATION). The mean population correlation was obtained by converting each of the observed correlation values to population correlation and then averaging it across the studies. This procedure eliminates any sampling error across studies (Hunter et al., 1982). As a correlation coefficient is not normally distributed and its variance is not constant, we converted the mean correlation values to Fisher's z-transformation. Fisher's z-transformation is an accurate variance stabilizing conversion method for correlation coefficient ( $\mathrm{Ha}-$ yakawa, 1987). 
Second, we computed the variance across studies (OBSERVED VARIANCE). In this process, sampling error adds to the variance of correlation across studies (Hunter et al., 1982) which needs to be eliminated.

Third, we calculated the effect of variance by the sampling error (SAMPLING ERROR VARIANCE). The sampling error that adds to the variance across studies can be eliminated by deducting sampling error variance from the observed variance previously calculated.

Fourth, we computed the percentage of observed variance due to the effect of sampling error (EXPLAINED VARIANCE).

Finally, we computed a $95 \%$ confidence interval (CONFIDENCE INTERVAL) for the relationships. Due to the variance in the sample size of different studies, we use z-transformation values obtained for the mean correlation.

The percentages obtained for 'explain variance' facilitates identifying the need for examining the effect of moderators for the independent variable. Peters et al. (1985) suggest that the moderator effect should be accounted for if sampling error variance is less than $60 \%$ of the observed variance. A $95 \%$ confidence interval is a range between -1 to $I$ and denotes the association between the independent variables and IT adoption. If the $95 \%$ confidence range falls between 0 and $\mathrm{I}$, it represents a positive association and if the interval is between 0 and $-I$, it is negatively associated.

\section{Results}

We obtained a total of 52 relationships from 39 studies that investigated one or more environmental or CEO attributes that influence IT adoption. The dependent variables for the study were adoption of IT (initiation, adoption-decision and implementation) and the independent variables considered for the studies were three environmental characteristics (competitive pressure, government support and external support) and four CEO characteristics (CEO attitude, manager's tenure, CEO innovativeness and CEO IT knowledge).

\section{I Meta-analysis summary of findings}

The study conducted meta-analysis for 3 environmental characteristics and 4 CEO characteristics that influenced the adoption of IT. We used studies that provided a correlation value for each of the environmental and CEO attributes. Twenty two studies were used to perform the meta-analysis procedures with 30 IT innovation adoption relationships.

Table 2 illustrates the result of the meta-analysis of environmental and CEO characteristics influencing the adoption of IT. For each independent variable, Table 2 shows total number of innovation considered for analysis (denoted INN STD), the total sample size (SAM SIZ), mean population correlation (MEN COR), observed variance (OBS VAR), sampling error due to variance (SAM VAR), the percentage of explain variance (EXP VAR) and $95 \%$ confidence interval (COF INT), respectively. The mean population correlation (MEN COR) gives the strength of significance for each individual characteristic. The percentage of explained variance (EXP VAR) indicates the possibility of examining the variable for moderator effects. The $95 \%$ confidence interval (MEN COR) indicates the association between the independent variable and IT adoption.

The meta-analysis result of $95 \%$ confidence interval confirmed the association (intervals do not include zero) between all independent variables and IT adoption. The mean correlation result of the meta-analysis verified the relationship between the attributes and IT adoption except manager's tenure. The study showed that external pressure, government support, CEO innovativeness, CEO attitude, CEO IT knowledge and competitive pressure had a weak significance (correlation value between \pm 0.10 to \pm 0.29 ) with IT adoption. 


\begin{tabular}{|c|c|c|c|c|c|c|c|}
\hline Independent Variables & INN STD & SAM SIZ & MEN COR & OBS VAR & SAM EVA & EXP VAR & COF INT \\
\hline Competitive Pressure & 16 & 7954 & 0.1039 & 0.0246 & 0.0020 & 8 & $0.08,0.13$ \\
\hline Government Support & 7 & 6063 & 0.2252 & 0.0193 & 0.0010 & 5 & $0.20,0.25$ \\
\hline External Pressure & 6 & 1134 & 0.238 & 0.0081 & 0.0047 & 59 & $0.18,0.30$ \\
\hline CEO A ttitude & 7 & 5018 & 0.2132 & 0.0043 & 0.0013 & 30 & $0.19,0.24$ \\
\hline$M$ anagers Tenure & 5 & 4652 & 0.0964 & 0.0021 & 0.0011 & 51 & $0.07,0.13$ \\
\hline CEO Innovativeness & 4 & 816 & 0.215 & 0.0108 & 0.0045 & 42 & $0.15,0.29$ \\
\hline CEO IT Knowledge & 13 & 8455 & 0.152 & 0.0166 & 0.0015 & 9 & $0.13,0.17$ \\
\hline \multicolumn{8}{|c|}{$\begin{array}{l}\text { N o. of Innovation Studied - IN N STD, Sample Size - SA M SIZ, M ean Correlation - M EN COR, Observed V ariance - OBS VAR } \\
\text { Sampling Error V ariance - SA M EVA, Explain V ariance - EXP VAR, 95\% Confidence Interval - COF INT }\end{array}$} \\
\hline
\end{tabular}

Table 2. Meta-analysis results of environmental factors

Managers tenure was found to be insignificant (correlation value between 0 to \pm 0.09 ) in our meta-analysis results, which supports the findings of Larsen (1993) and Sharma and Rai (2003). The results of moderator effects for manager's tenure would better explain the insignificant outcome.

\subsection{Moderator effect on the relationship between independent variables and IT adoption}

The meta-analysis procedure provides an explanation of inconsistencies in the findings of the individual studies by examining different moderator conditions that affect the relationship between dependent and independent variables (Rosenthal and DiMatteo, 200I). In order to examine the effect of the moderators, studies were divided into subgroups of each moderator conditions.

As suggested by Peters et al. (1985), for all independent variables with sampling error variance less than $60 \%$ of observed variance we performed meta-analysis of moderator effects. Meta-analysis results showed that the percentage of explained variances of all factors was less than $60 \%$. The findings of the effects of two moderators for the relationship between the environmental and CEO characteristics are illustrated in the following sub-sections.

\subsection{Findings of the effect of 'stage of innovation' moderator}

Table 3 illustrates the meta-analysis results of 'stage of innovation' moderator effects on the relationship between environmental and CEO characteristics with IT adoption.

The results of the mean correlation showed a weak significance (correlation value between \pm 0.10 to \pm 0.29 ) for all the factors considered in the adoption-decision stages of innovation adoption. In addition, a $95 \%$ confidence interval of adoption-decision stage for all factors considered shows a positive association (interval do not include zero) for the relationship with IT adoption. For the implementation stage of IT adoption, the results showed a positive association (interval does not include zero) with a weak significance (correlation value between \pm 0.10 to \pm 0.29 ) for external pressure while competitive pressure and CEO IT knowledge showed an insignificant relationship (correlation value between 0 to \pm 0.09 ) with IT adoption. Due to the lack of data available, the study was not able to perform meta-analysis for the implementation stage of other factors. In addition, the study could not perform meta-analysis moderator effects for the initiation subgroup of stage of innovation moderator.

One of the interesting results of the stage of innovation moderator appeared in the competitive pressure and external pressure. The mean correlation results suggest that external pressure was more significant in terms of magnitude for adoption-decision stage compared to 
the implementation stage of IT adoption. This result is consistent with the findings of lacovou et al. (1995) and Premkumar and Ramamurthy (1995). The mean correlation results suggest that competitive pressure was found to have weak significance (correlation value between \pm 0.10 to \pm 0.29 ) for adoption-decision stage while insignificant (correlation value between 0 to $\pm 0.09)$ for the implementation stage of IT adoption. One credible justification might be that organizations initiate IT adoption due to pressure from competitors and demands from potential trading partners and customers, but once the decision to adopt has been approved by the organization, they are more willing to implement and utilize the innovation with favourable expectations.

\begin{tabular}{|c|c|c|c|c|c|c|c|}
\hline M oderator & INN STD & SAM SIZ & MEN COR & OBS VAR & SAM EVA & EXP VAR & COF INT \\
\hline \multicolumn{8}{|c|}{ Competitive Pressure } \\
\hline Initiation & 1 & 1857 & 0.1900 & 0.0000 & 0.000 & 0 & $0.15,0.24$ \\
\hline A doption & 10 & 3557 & 0.1161 & 0.0419 & 0.0027 & 7 & $0.08,0.15$ \\
\hline Implementation & 5 & 2540 & 0.0239 & 0.0063 & 0.0020 & 31 & $-0.01,0.06$ \\
\hline Mixed & 0 & & & & & & \\
\hline \multicolumn{8}{|c|}{ G overnment Support } \\
\hline Initiation & 1 & 1857 & 0.4200 & 0.0000 & 0.000 & 0 & $0.40,0.49$ \\
\hline A doption & 5 & 2349 & 0.1306 & 0.0064 & 0.0021 & 32 & $0.09,0.17$ \\
\hline Implementation & 1 & 1857 & 0.1500 & 0.0000 & 0.000 & 0 & $0.11,0.20$ \\
\hline Mixed & 0 & - & - & - & - & - & - \\
\hline \multicolumn{8}{|c|}{ External pressure } \\
\hline Initiation & 0 & - & - & - & - & - & - \\
\hline A doption & 4 & 796 & 0.2717 & 0.0046 & 0.0043 & 94 & $0.21,0.35$ \\
\hline Implementation & 2 & 338 & 0.1577 & 0.0071 & 0.0057 & 79 & $0.05,0.27$ \\
\hline Mixed & 0 & - & - & - & - & - & - \\
\hline \multicolumn{8}{|c|}{ CEO Attitude } \\
\hline Initiation & 1 & 1276 & 0.200 & 0.000 & 0.000 & 0 & $0.15,0.26$ \\
\hline A doption & 5 & 2466 & 0.242 & 0.007 & 0.002 & 27 & $0.21,0.29$ \\
\hline Implementation & 1 & 1276 & 0.170 & 0.000 & 0.000 & 0 & $0.12,0.23$ \\
\hline Mixed & 0 & - & - & - & - & - & - \\
\hline \multicolumn{8}{|c|}{ M anagers Tenure } \\
\hline Initiation & 1 & 1276 & 0 & 0.0049 & 0.001 & 16 & $-0.05,0.05$ \\
\hline A doption & 2 & 2001 & 0.130 & 0.000 & 0.000 & 0 & $0.09,0.17$ \\
\hline Implementation & 1 & 1276 & 0.090 & 0.000 & 0.000 & 0 & $0.04,0.14$ \\
\hline Mixed & 1 & 99 & -0.160 & 0.000 & 0.000 & 0 & $-0.36,0.04$ \\
\hline \multicolumn{8}{|c|}{ CE $O$ Innovativeness } \\
\hline Initiation & 0 & - & - & - & - & - & - \\
\hline A doption & 3 & 522 & 0.242 & 0.015 & 0.005 & 35 & $0.16,0.33$ \\
\hline Implementation & 1 & 294 & 0.167 & 0.000 & 0.000 & 0 & $0.05,0.28$ \\
\hline $\begin{array}{l}\text { Mixed } \\
\text { CEO IT K }\end{array}$ & 0 & - & - & - & - & - & - \\
\hline Initiation & 1 & 1276 & 0.0000 & 0.0196 & 0.0196 & 100 & $-0.05,0.05$ \\
\hline A doption & 8 & 4320 & 0.2256 & 0.0156 & 0.0017 & 11 & $0.20,0.26$ \\
\hline Implementation & 3 & 2760 & 0.0388 & 0.0049 & 0.0011 & 22 & $0.00,0.08$ \\
\hline Mixed & 1 & 99 & 0.2100 & 0.0000 & 0.000 & 0 & $0.01,0.41$ \\
\hline \multicolumn{8}{|c|}{ No. of Innovation Studied - IN N STD, Sample Size - SA M SIZ, M ean Correlation - M EN COR, Observed V ariance - OBS VA R } \\
\hline
\end{tabular}

Table 3. Meta-analysis 'stage of innovation' moderator effect results 
Another interesting result of the meta-analysis moderator effect of stage of innovation was adoption-decision and implementation subgroup for CEO IT knowledge. The results were found to be insignificant (correlation value between 0 to \pm 0.09 ) for the implementation stage but a weak significance (correlation value between \pm 0.10 to \pm 0.20 ) for the adoption-decision stage. This result was consistent with findings of Thong (1999) and Al-Gahtani (2004). The deduction from these results might be that once IT has been adopted, influence of CEO is less important for the diffusion of innovation.

Instead, at this stage, innovation and organizational factors become more considerable than the individual characteristics of the organizational leader.

\subsubsection{Findings of the effect of 'type of innovation' moderator}

The results of the meta-analysis of 'type of innovation' moderator effect for the relationship between environmental and CEO attributes with IT adoption is shown in Table 4.

\begin{tabular}{|c|c|c|c|c|c|c|c|}
\hline Moderator & INN STD & SAM SIZ & MEN COR & OBS VAR & SAM EVA & EXPVAR & COF INT \\
\hline \multicolumn{8}{|c|}{ Competitive Pressure } \\
\hline Product & 11 & 6798 & 0.126 & 0.024 & 0.002 & 6 & $0.10,0.15$ \\
\hline Process & 0 & - & - & - & - & - & - \\
\hline Mixed & 5 & 1156 & -0.028 & 0.006 & 0.004 & 77 & $-0.09,0.03$ \\
\hline \multicolumn{8}{|c|}{ Government Support } \\
\hline Product & 7 & 6063 & 0.225 & 0.019 & 0.001 & 5 & $0.20,0.25$ \\
\hline Process & 0 & - & - & - & - & - & - \\
\hline Mixed & 0 & - & - & - & - & - & - \\
\hline \multicolumn{8}{|c|}{ External pressure } \\
\hline Product & 4 & 732 & 0.2878 & 0.0036 & 0.0036 & 100 & $0.22,0.37$ \\
\hline Process & 0 & - & - & - & - & - & - \\
\hline Mixed & 2 & 402 & 0.1465 & 0.0034 & 0.0034 & 100 & $0.05,0.25$ \\
\hline \multicolumn{8}{|c|}{ CEO Attitude } \\
\hline Product & 2 & 299 & 0.398 & 0.001 & 0.001 & 100 & $0.31,0.53$ \\
\hline Process & 4 & 4553 & 0.198 & 0.002 & 0.001 & 45 & $0.17,0.23$ \\
\hline Mixed & 1 & 166 & 0.311 & 0.000 & 0.000 & 0 & $0.17,0.48$ \\
\hline \multicolumn{8}{|c|}{ M anagers $\mathrm{T}$ enure } \\
\hline Product & 0 & - & - & - & - & - & - \\
\hline Process & 5 & 4652 & 0.096 & 0.002 & 0.001 & 51 & $0.07,0.12$ \\
\hline Mixed & 0 & - & - & - & - & - & - \\
\hline \multicolumn{8}{|c|}{ CEO Innovativeness } \\
\hline Product & 1 & 62 & 0.570 & 0.000 & 0.000 & 0 & $0.39,0.90$ \\
\hline Process & 0 & - & & & & - & \\
\hline Mixed & 3 & 754 & 0.186 & 0.000 & 0.000 & 0 & $0.12,0.26$ \\
\hline \multicolumn{8}{|c|}{ CEO IT K nowledge } \\
\hline Product & 2 & 572 & 0.4688 & 0.0009 & 0.0009 & 100 & $0.43,0.59$ \\
\hline Process & 8 & 7129 & 0.1213 & 0.0087 & 0.0011 & 13 & $0.10,0.15$ \\
\hline Mixed & 3 & 754 & 0.1971 & 0.0156 & 0.0037 & 24 & $0.13,0.27$ \\
\hline & $\begin{array}{l}\text { INN STD, } \\
\text { AM EVA, }\end{array}$ & $\begin{array}{l}\text { nple Size - } S \\
\text { lain V arianc }\end{array}$ & $\begin{array}{l}\text { M SIZ, M ean } \\
\text { - EXP VAR, }\end{array}$ & $\begin{array}{l}\text { orrelation - M } \\
\% \text { Confidence }\end{array}$ & $\begin{array}{l}\text { N COR, Obse } \\
\text { nterval - COF }\end{array}$ & $\begin{array}{l}\text { ed V ariance - } \\
\text { IT }\end{array}$ & \\
\hline
\end{tabular}

Table 4. Meta-analysis 'type of innovation' moderator effect results 
The results of the mean correlation of product subcategory showed a weak significance (correlation value between \pm 0.10 to \pm 0.29 ) for the relationship between all the environmental attributes and IT adoption. The $95 \%$ confidence interval for these factors showed a positive association (interval does not include zero) for the relationship with IT adoption. Due to unavailability of data, the study was not able to perform meta-analysis of the process sub-category for any of the environmental characteristics.

Two notable results of 'type of innovation' moderator effect were the relationship between CEO attitude and CEO IT knowledge with IT adoption. Results showed a moderate significance (correlation value between \pm 0.30 to \pm 0.49 ) for the relationship between both CEO attitude and CEO IT knowledge with IT adoption for product innovation and a weak significance (correlation value between \pm 0.10 to \pm 0.29 ) for process innovation. These results might be explained by the fact that process innovation involves replacing the entire system or work procedure, CEO's with positive attitude or sound knowledge of IT have various other organizational and technological considerations. Unlike process innovation, product innovation does not involve change of an entire system and CEO's with a positive attitude face less restrictions on executing their innovative strategy.

\section{Discussion}

In this study a systematic review of IT innovation literature was carried out to find the major environmental and CEO characteristics that influence the adoption of IT. A metaanalysis of findings was performed to analyse the relative strength and impact of each of the environmental and CEO attributes to IT adoption. In addition, the effect of two moderator conditions that might have an impact on the relationship between individual attributes and IT adoption was also examined. The environmental factors considered in the study were competitive pressure, government support and external pressure. The CEO characteristics considered were CEO attitude, manager's tenure, CEO innovativeness and CEO IT knowledge. The meta-analysis results confirmed a weak significance for external pressure, government support, CEO innovativeness, CEO attitude, CEO IT knowledge and competitive pressure to IT adoption in organizations. However, manager's tenure was found to be insignificant for the adoption of IT in an organization.
The results of the meta-analysis showed that external pressure was an important attribute for the adoption of IT in organization. This means that a recommendation from a strategic trading partner and a demand from a key customer to adopt a certain IT innovation influence the adoption of IT by organizations. However, the magnitude of this factor was less significant than we anticipated. This result was unpredictable especially for small organizations, as they are highly dependent on their trading partner and customers.

The meta-analysis found a weak significance for government support in the adoption of IT. The contribution of government in the adoption of IT in organizations are mainly through developing dynamic policies, providing financial incentives, building communication incentives and promoting IT in industries. The result suggests that organizations are willing to adopt IT despite the support and incentives from the government. The strength of the significance of government support to IT adoption was not as strong as expected. One argument is that as IT innovations are rapidly changing phenomenon and the adoption of IT tends to be driven by individual initiatives rather than institutional support.

CEO innovativeness was found to have a weak significance to the adoption of IT. An innovative CEO will be prepared to take any risk to find new ways of improving the operations of the organization. Innovative CEO's are more likely to adopt novel technologies that have not been tried in similar circumstances in anticipation of a positive outcome.

The CEO attitude was found have a weak significance to the adoption of IT. The CEOs who have an optimistic approach in the adoption of IT are more likely to adopt IT. In small businesses, the CEO is often the owner and sole decision maker. Hence it was predicted that appreciation of the relative advantages and benefits of IT by the CEO would be an important determinant of IT adoption. It is possible that due to the widespread awareness of the IT, the majority of CEOs perceived the adoption of IT positively and it is the other organizational and innovation attributes that determine its implementation.

CEO IT knowledge is important to realize the benefits of an innovation adoption. However, our meta-analysis found CEO IT knowledge to have only a weak significance for the adoption of IT. As with other CEO characteristics, the impact of CEO IT knowledge has been overshadowed by organizational and innovation factors that dictate the adoption processes in organizations. 
It is believed that pressure from competitive firms plays a role in the adoption of IT in organizations. However, our study found competitive pressure to have only a weak significance for the adoption of IT. Most of the literature argued that the greater the competition among similar organizations, the more likely the organization considers IT adoption to gain a competitive edge (lacovou et al., 1995). Zhu et al. (2006b) found that competition is more important for the initiation stages of adoption but less important for the assimilation stages of adoption. The meta-analysis could not verify the relationship between competitive pressure and IT adoption for initiation stage due to unavailability of data sets. To fully understand the impact of competitive pressure, researchers need to investigate the effects at different stages of IT adoption.

The study found manager's tenure insignificant for IT adoption. It is widely expected that manager's with experience are more capable of directing the adoption smoothly, by creating a favourable environment for adoption and making sure that the new innovation integrates well into the existing processes. However, one possible explanation of our finding might be that IT has been widely used by many organizations and different IT applications are well known to everyone. Similar innovations have been used by related organizations and its applications are well-known within that community. Hence, a manager's experience of the organizational setting does not contribute to realizing the relevance and benefits of an innovation, allowing smooth adoption and implementation process.

\section{Limitations}

This study has several limitations and in interpreting the results of this study its limitations need be taken into account. The major limitation of this analysis was the lack of studies on environmental and CEO characteristics of IT adoption. From the literature that examined the factors influencing adoption of IT, only 39 studies examined one or more environmental or CEO characteristics. Among these, we used studies that performed correlation analysis for the meta-analysis which limits our analysis to 22 studies. If the meta-analysis was done with more sample studies, the result could have been more accurate and better explained. Similarly, the major hindrance in performing the moderator factor effects for individual factor was also the lack of available data sets for different sub-categories.
Any review study or meta-analysis is subject to publication bias. Scargle (2000) stated that when statistical results are combined from different studies publication bias arises because it is more likely to published research results that found to be statistically significant. To avoid publication bias, we took every step to include all literature from different categories of Journal that addresses environmental and CEO characteristics influencing the adoption of IT. Exhaustive search of the literature allowed us to select studies that appeared in different levels of IS journals with varying contributions.

\section{Conclusion}

The results obtained have certain implications for research and practice. The study enhances our understanding of the environmental and CEO determinants of IT adoption. Results serve as a guideline for practitioners to identify and address the facilitating and inhibiting issues in the context of environmental and CEO attributes in the process of IT adoption. On the other hand, the study found various gaps in current literature.

Our result suggests that managers and vendors need to address some of these factors in the IT adoption processes. The result of moderator effect showed some factors need to be addressed more thoroughly in specific conditions and circumstances than others in the adoption and implementation of IT. The factors and the conditions that need to be considered for different stages of IT adoption have also been highlighted in the results which would help to achieve a successful adoption process.

Lack of data meant that the study fell short of identifying the different moderating conditions that influenced the relationship between independent and dependent variables. More empirical research is required to fully understand different moderating condition on the relationships. We encourage replication of studies in this area and to that end; all data used in this study can be made available upon request of the lead author. 


\section{References}

ABEREIJO, I. O., Adegbite, S. A., Ilori, M. O., Adeniyi, A. A. And Aderemi, H. A. (2009). Technological Innovation Sources and Institutional Support for Manufacturing Small and Medium Enterprises in Nigeria. Journal of Technology Management and Innovation, 4 (2), 82-89.

ALAM, S. S. (2009). Adoption of Internet in Malaysian SMEs. Journal of Small Business and Enterprise Development, 16 (2), 240-255.

AL-GAHTANI, S. S. (2004). Computer Technology Acceptance Success Factors in Saudi Arabia: An Exploratory Study. Journal of Global Information Technology Management, 7 (I), 5-29.

ANGLE, H. L. and Van de Ven, A. H. (2000). Suggestions for Managing the Innovation Journey, In: A. H. Van de Ven, H. L. Angle and M. S. Poole (editions), Research on the Management of Innovation: The Minnesota Studies, Oxford University Press, New York, 663-697.

BRADFORD, M. and Florin, J. (2003). Examining the Role of Innovation Diffusion Factors on the Implementation Success of Enterprise Resource Planning (ERP) Systems. International Journal of Accounting Information Systems, 4 (3), 205-225.

CARTER, J., Franklin J., Jambulingam T., Gupta V. K. and Melone N. (200l). Technological Innovations: A Framework for Communicating Diffusion Effects. Information \& Management, 38 (5), 277-287.

CHAN, S. C. H. and Ngai E. W. T. (2007). A Qualitative Study of Information Technology Adoption How Ten Organizations Adopted Web-Based Training. Information Systems Journal, 17 (3), 289-3I5.

CHONG,S.(2004). Electronic CommerceAdoptionbySmall and Medium Enterprises in Australia: An Empirical Study of Influencing Factors. [Online] available at: http://is2.Ise. ac.uk/asp/aspecis/20040033.pdf [accessed February 20II].

CHUANG, T., Nakatani, K. and Zhou, D. (2009). An Exploratory Study of the Extent of Information Technology Adoption in SMEs: An Application of Upper Echelon Theory. Journal of Enterprise Information Management, $22(\mathrm{I} / 2), 183-196$.
CHWELOS, P., Benbasat, I. and Dexter, A. S. (200I). Research Report: Empirical Test of an EDI Adoption Model. Information Systems Research, 12 (2), 304-32I.

COHEN, L., Manion, L. and Morrison, K. (2007). Research Methods in Education, Routledge.

COOPER, H. M., Hedges, L. V. and Valentine, J. C. (2009). The Hand Book of Research Synthesis and Meta-analysis, 2nd edition, Russell Sage Foundation, New York.

COOPER, R. B. and Zmud, R. W. (1990). Information Technology Implementation Research: A Technological Diffusion Approach. Management Science, 36 (2), I23-I39.

CRAGG, P. B. and King, M. (1993). Small-Firm Computing: Motivators and Inhibitors. MIS Quarterly, 17 (I), 47-60.

DAMANPOUR, F. (199I). Organizational Innovation: A Meta-analysis of Effects of Determinants and Moderators. Academy of Management Journal, 34 (3), 555-590.

DAMANPOUR, F. and Gopalakrishnan, S. (200I). The Dynamics of the Adoption of Product and Process Innovations in Organizations. Journal of Management Studies, 38 (I), 45-65.

DAMANPOUR, F. and Schneider, M. (2006). Phases of the Adoption of Innovation in Organizations: Effects of Environment Organization and Top Managers. British Journal of Management, 17 (3), 215-236.

DAMANPOUR, F. and Schneider, M. (2009). Characteristics of Innovation and Innovation Adoption in Public Organizations: Assessing the Role of Managers. Journal of Public Administration Research \& Theory, 19 (3), 495-522.

DE VAUS, D. (2002). Survey in Social Research, 5th edition, Routledge.

ELLIS, P. D. (2010). The Essential Guide to Effect Sizes: Statistical Power, Meta-Analysis, and the Interpretation of Research Results, Cambridge University Press, Cambridge. 
FICHMAN, R. G. and Carroll, W. E. (1999). The Diffusion and Assimilation of Information Technology Innovations In: R.W. Zmud (edition) Framing the Domains of IT Management: Projecting the Future... Through the Past, Cincinnati, OH: Pinnaflex Educational Resources, Inc.

GABLE, G. G. and Raman, K. S. (1992). Government Initiatives for IT Adoption in Small Businesses: Experiences of the Singapore Small Enterprise Computerization Programme. International InformationSystems, I (I), 68-93.

GATIGNON, H. and Robertson, T. S. (1989). Technology Diffusion: An Empirical Test of Competitive Effect. Journal of Marketing, 53 (I), 35-49.

GLASS, G. V., McGaw, B. and Smith, M. L. (198I). Metaanalysis in Social Research. Beverly Hills, CA: Sage.

GOPALAKRISHNAN, S. and Damanpour, F. (1997). Innovation Research in Economics, Sociology, and Technology Management. Omega, International Journal of Management Science, 25 (I), 15-28.

GRANDON, E. and Pearson, J. M., (2004a). E-commerce Adoption: Perception of Managers/Owners of Small and Medium Sized Firms in Chile. Communications of the Association for Information Systems, 13, 81-102.

GRANDON, E. and Pearson, J. M. (2004b). Electronic Commerce Adoption: An Empirical Study of Small and Medium US Businesses. Information \& Management, 42 (I), 197-216.

GROVER, V. and Goslar, M. D. (1993). The Initiation, Adoption and Implementation of Telecommunications Technologies in U.S. Organizations. Journal of Management Information Systems, 10 (I), 14I- 163.

GUZZO, R. A., Jackson, S. E. and Katzell, R. A. (1987). Meta-analysis Analysis. Research in Organizational Behaviour, 9, 407-442.

HAGE, J. and Aiken, M. (1970). Social Change in Complex Organizations. Random House, New York.

HAYAKAWA, T. (1987). Normalizing and Variance Stabilizing Transformation of Multivariate Statistics under an Elliptical Population. Annuals of the Institute of Statistical Mathematics, 39 (I), 299-306.
HUBER, G. P., Sutcliffe, K. M., Miller, C. C. and Glick, W. M. (1993). Understanding and Predicting Organizational Change, In: G. P. Huber and W. H. Glick, (editions), Organizational Change and Redesign. Oxford University Press, New York.

HUNTER, J. E., Schmidt, F. L. and Jackson, G. B. (1982). Meta-analysis. Beverly Hills, CA: Sage.

IACOVOU, C. L., Benbasat, I. and Dexter, A. S. (1995). Electronic Data Interchange and Small Organization: Adoption and Impact of Technology. MIS Quarterly, 19 (4), 465-487.

JEON, B. N., Han, K. S. and Lee, M. J. (2006). Determining Factors for the Adoption of E-business the Case of SMEs in Korea. Applied Economics, 38 (16), 1905-1916.

KHALID, S. S. and Brian, D. J. (2004). An Exploratory Study to Identify the Critical Factors Affecting the Decision to Establish Internet Based Inter-organizational Information Systems. Information \& Management, 4 I (6), 697-706.

KIMBERLY, J. R. and Evanisko, M. J. (198I). Organizational Innovation: The Influence of Individual Organizational and Contextual Factors on Hospital Adoption of Technological and Administrative Innovations. Academy of Management Journal, 24 (4), 689-7I3.

KLEIN, K. J. and Sorra, J. S. (1996). The Challenge of Innovation Implementation. Academy of Management Review, 2I (4), I055-I080.

KOWTHA, N. R. and Choon, T. W. I. (200I). Determinants of Website Development: A Study of Electronic Commerce in Singapore. Information \& Management, 39 (3), 227-242.

KUAN, K. K. Y. and Chau, P. Y. K. (200I). A PerceptionBased Model for EDI Adoption in Small Businesses using a Technology, Organization, Environment Framework. Information \& Management, 38 (8), 507-52I.

KWON, T. H. and Zmud, R. W. (1987). Unifying the Fragmented Models of Information Systems Implementation, In: J. R. Boland and R. Hirschheim (editions), Critical Issues in Information Systems Research. Wiley, New York. 
LAI, V. S. and Guynes, J. L. (1997). An Assessment of the Influence of Organizational Characteristics on Information Technology Adoption Decision: A Discriminative Approach. IEEE Transaction on Engineering Management, 44 (2), I46-I57.

LARSEN, T. J. (1993). Middle Managers' Contribution to Implemented Information Technology Innovation. Journal of Management Information System, 10 (2), I55-176.

LAW, C. C. H. and Ngai, E. W. T. (2007). ERP Systems Adoption: An Exploratory Study of the Organizational Factors and Impacts of ERP Success. Information \& Management, 44 (4), 4I8-432.

LERTWONGSATIEN, C. and Wongpinunwatana, N. (2003). E-commerce Adoption in Thailand: An Empirical Study of Small and Medium Enterprises (SMEs). Journal of Global Information Technology Management, 6 (3), 67-83.

LIN, C. (2008), An Empirical Study on Logistics Service Providers' Intention to Adopt Green Innovations. Journal of Technology Management and Innovation, 3 (I), 17-26.

LOOI, H. C. (2005). E-Commerce Adoption in Brunei Darussalam: A Quantitative Analysis of Factors Influencing its adoption. Communications of the Association for Information Systems, 15, 61-8I.

MEHRTENS, J., Cragg, P. B. and Annette M. M. (200I). A Model of Internet Adoption by SMEs. Information \& Management, 39 (3), 165-176.

MEYER, A. D. and Goes, J. B. (1988). Organizational Assimilation of Innovation: A Multilevel Contextual Analysis. Academy of Management Journal, 3I (4), 897-923.

MIRCHANDANI, D. A. and Motwani J. (200I). Understanding Small Business Electronic Commerce Adoption: An Empirical Analysis. Journal of Computer Information Systems, 4I (3), 70-74.

PETERS, L. H., Hartke, D. D. and Pohlmann J. T. (1985). Fiedler's Contingency Theory of Leadership: An Application of the Meta-analysis Procedures of Schmidt and Hunter. Psychological Bulletin 97, 274-285.
PINHEIRO, A. B. (20I0). How Do Managers Control Technology-Intensive Work? Journal of Technology Management and Innovation, 5 (2), I-I2.

POON, S. and Swatman, P. (1998). Small Business Internet Commerce Experience: A Longitudinal Study. In the Proceedings of IIth International Bled E-Commerce Conference, Bled, Slovenia, June 8-10th, 295-309.

PREMKUMAR, G. and Ramamurthy, K. (1995). The Role of Inter-Organizational and Organizational Factors on the Decision Mode for the Adoption of Inter-Organizational Systems. Decision Science, 26 (3), 303-336.

PREMKUMAR, G. and Roberts, M. (1999). Adoption of New Information Technologies in Rural Small Businesses. The International Journal of Management Science, 27 (4), 467-484.

QUADDUS, M. and Hofmeyer, G. (2007). An Investigation into the Factors Influencing the Adoption of B2B Trading Exchanges in Small Businesses. European Journal of Information Systems, 16, 202-215.

ROGERS, E. M. (1983). Diffusion of Innovations, 3rd edition, Free Press, New York.

ROGERS, E. M. (1995). Diffusion of Innovations, Free Press, New York.

ROSENTHAL, R. and DiMatteo, M. R. (200I). Metaanalysis: Recent Development in Qualitative Methods for Literature Reviews. Annual Review ofPsychology, 52, 59-82.

SCARGLE, J. D. (2000). Publication Bias: The 'File-Drawer' Problem in Scientific Inference. Journal of Scientific Exploration, 14 (I), 91-106.

SCUPOLA, A. (2003). The Adoption of Internet Commerce by SMEs in the South of Italy: An Environmental, Technological and Organizational Perspective. Journal of Global Information Technology Management, 6 (I), 52-7I.

SEYAL, A. H., Awais, M. M., Shamail, S. and Andleeb (2004). Determinants of Electronic Commerce in Pakistan: Preliminary Evidence from Small and Medium Enterprises. Electronic Markets, 14 (4), 372-387. 
SEYAL, A. H. and Rahman, M. N. A. (2003). A Preliminary Investigation of E-Commerce Adoption in Small and Medium Enterprises in Brunei. Journal of Global Information Technology Management, 6 (2), 6-26.

SEYAL, A. H., Rahman, M. N. A. and Mohammad, H. A. Y. H. A. (2007). A Quantitative Analysis of Factors Contributing Electronic Data Interchange Adoption among Bruneian SMEs. Business Process Management Journal, 13 (5), 728-746.

SHARMA, S. and Rai, A. (2003). An Assessment of the Relationship between ISD Leadership Characteristics and IS Innovation Adoption in Organizations. Information \& Management, 40 (5), 39I-40I.

TANG, S. (2000). An Impact Factor Model of Intranet Adoption: An Exploratory and Empirical Research. Journal of Systems and Software, 5 I (3), 157-173.

TEO, T. S. H., Lin, S. and Lai, K. (2009). Adopters and NonAdopters of E-procurement in Singapore: An Empirical Study. Omega, International Journal of Management Science, 37 (5), 972-987.

THOMPSON, V. A. (1965). Bureaucracy and Innovation. Administrative Science Quarterly, I0 (I), I-20.

THONG, J. Y. L. (1999). An Integrated Model of Information Systems Adoption in Small Businesses. Journal of Management Information Systems, I5 (4), I87-2I4.

THONG, J. Y. L. and Yap, C. (1995). CEO Characteristics, OrganizationalCharacteristicsand Information Technology Adoption in Small Businesses. Omega, International Journal of Management Science, 23 (4), 429- 442.

TORNATSKY, L. G. and Fleischer, M. (1990). The Process of Technological Innovation, Lexington Books.

TSAO, H., Lin, K. H. C. and Lin, C. (2004). An Investigation of Critical Success Factors in the Adoption of B2B-EC by Taiwanese Companies. The Journal of American Academy of Business, Cambridge.

UTTERBACK, J. M., and Abernathy, W. J. (1975). A Dynamic Model of Process and Product Innovation. Omega, The International Journal of Management Science, 3 (6), 639-656.
WANG, S. and Cheung, W. (2004). E-Business Adoption by Travel Agencies: Prime Candidates for Mobile E-Business. International Journal of Electronic Commerce, 8(3), 43-63.

ZALTMAN, G., Duncan, R. and Holbek J. (1973). Innovations and Organizations, Wiley, New York.

ZALTMAN, G., Duncan, R. and Holbeck, J. (1984). Innovations \& Organizations, Malabar, Florida.

ZHU, K., Dong, S., Xu, S. and Kraemer, K. L. (2006a) Innovation Diffusion in Global Contexts: Determinants of Ppost-adoption Digital Transformation of European Companies. European Journal of Information Systems, 15 (6), 60I-6I6.

ZHU, K., Kraemer, K. L. and Xu, S. (2006b). The Process of Innovation Assimilation by Firms in Different Countries: A Technology Diffusion Perspective on E-Business. Management Science, 52 (10), I557-1576.

ZMUD, R. W. (1982). Diffusion of Modern Software Practices: Influence of Centralization and Formalization. Management Science, 28, 142I-I43I. 


\section{Appendix}

\begin{tabular}{|c|c|c|c|c|c|c|c|c|c|c|c|c|c|c|c|c|c|c|c|c|}
\hline \multirow[t]{2}{*}{ Study } & \multirow[t]{2}{*}{ Innovation } & \multirow{2}{*}{$\begin{array}{l}\text { SAM } \\
\text { SIZE }\end{array}$} & \multirow{2}{*}{$\begin{array}{l}\text { STG } \\
\text { ADP }\end{array}$} & \multirow{2}{*}{$\begin{array}{l}\text { TYP } \\
\text { INO }\end{array}$} & \multirow{2}{*}{$\begin{array}{l}\text { IND } \\
\text { TYP }\end{array}$} & \multirow{2}{*}{$\begin{array}{l}\text { ORG } \\
\text { CAT }\end{array}$} & \multirow[t]{2}{*}{$\mathrm{ANA}$} & \multicolumn{2}{|c|}{ CEO ATT } & \multicolumn{2}{|c|}{ MNG TEN } & CEO INO & \multicolumn{2}{|c|}{ CEO KLG } & \multicolumn{2}{|c|}{ COMPRE } & \multicolumn{2}{|c|}{ GOVSUP } & \multicolumn{2}{|c|}{ EXT PRE } \\
\hline & & & & & & & & $\mathrm{s}$ & CRV & $\mathrm{s}$ & CRV & S CRV & $\mathrm{s}$ & CRV & $\mathrm{s}$ & CRV & $\mathrm{s}$ & CRV & $\mathbf{S}$ & CRV \\
\hline Alam (2003) & Internet & 368 & ADP & PRD & MIX & SML & COR & & & & & & $\mathrm{P}$ & 0.446 & & & & & & \\
\hline \multirow[t]{2}{*}{ Al-Gahtani (2004) } & \multirow{2}{*}{ IT } & 1190 & ADP & PRC & MIX & MIX & COR & & & & & & $\mathrm{P}$ & 0.242 & & & & & & \\
\hline & & 1190 & IMP & PRC & MIX & MIX & $\mathrm{COR}$ & & & & & & $\mathrm{N}$ & -0.038 & & & & & & \\
\hline Bradford and Florin (2003) & ERP & $\$ 1$ & IMP & PRD & MFG & LRG & $\mathrm{COR}$ & & & & & & & & $P$ & -0.119 & & & & \\
\hline Chan and Ngai (2007) & Internet & 10 & ADP & PRD & MIX & MIX & DES & & & & & & $\mathrm{P}$ & & & & & & $P$ & \\
\hline Chong (2004) & E-Commerce & 115 & ADP & PRD & MIX & SML & REG & & & & & & & & $P$ & & $\mathrm{P}$ & & $P$ & \\
\hline Chuang et al. (2009) & IT & 97 & ADP & PRC & $\mathrm{SRV}$ & SML & COR & & & & & & $\mathrm{P}$ & 0.487 & & & & & & \\
\hline Chwelos et al. (2001) & EDI & 317 & ADP & PRD & MIX & MIX & $\mathrm{COR}$ & & & & & & & & $P^{P}$ & 0.457 & & & $P$ & 0.341 \\
\hline Cragg and and King (1993) & Computing & 6 & IMP & PRC & MFG & SML & DES & & & & & $P$ & & & $\mathrm{~N}$ & & & & & \\
\hline \multirow{3}{*}{$\begin{array}{l}\text { Damanpour and Schneider } \\
(2006)\end{array}$} & & 1276 & INI & PRC & MIX & MIX & COR & $\mathrm{P}$ & 0.200 & $\mathrm{P}$ & 0.070 & & $\mathrm{~N}$ & 0.140 & & & & & & \\
\hline & IT & 1276 & ADP & PRC & MIX & MIX & COR & $P$ & 0.170 & $\mathrm{P}$ & 0.130 & & $\mathrm{~N}$ & 0.110 & & & & & & \\
\hline & & 1276 & IMP & PRC & MIX & MIX & COR & $\mathrm{P}$ & 0.170 & $\mathrm{P}$ & 0.090 & & $\mathrm{~N}$ & 0.110 & & & & & & \\
\hline $\begin{array}{l}\text { Damanpour and Schneider } \\
(2009)\end{array}$ & IT & 725 & ADP & PRC & $\mathrm{SRV}$ & MIX & $\mathrm{COR}$ & $P$ & 0.290 & $\mathrm{P}$ & 0.130 & & $\mathrm{P}$ & 0.130 & & & & & & \\
\hline $\begin{array}{l}\text { Grandon and Pearson } \\
(2004 a)\end{array}$ & E-Commerce & 83 & ADP & PRD & MIX & SML & DIS & $P$ & & & & & & & & & & & $P$ & \\
\hline $\begin{array}{l}\text { Grandon and Pearson } \\
(2004 b)\end{array}$ & E-commerce & 100 & $\mathrm{ADP}$ & PRD & MIX & SML & OTH & $\mathrm{P}$ & & & & & & & & & & & $P$ & \\
\hline \multirow[t]{3}{*}{ Iacovou et al. (1995) } & & & & & & & & & & & & & & & & & & & & \\
\hline & EDI & 7 & ADP & PRD & MIX & SML & DES & & & & & & & & & & & & P & \\
\hline & & 7 & $\mathrm{IMP}$ & PRD & MIX & SML & DES & & & & & & & & & & & & $\mathrm{N}$ & \\
\hline Jeon et al., (2006) & E-business & 204 & ADP & PRD & MIX & SML & $\mathrm{COR}$ & $P$ & 0.420 & & & & $\mathrm{P}$ & 0.510 & $\mathrm{~N}$ & 0.100 & $P$ & 0.310 & & \\
\hline Khalid and Brian (2004) & $\begin{array}{l}\text { Inter- } \\
\text { organizational } \\
\text { Information } \\
\text { Systems }\end{array}$ & 87 & ADP & PRC & MIX & MIX & ОТН & & & & & & & & $P^{P}$ & & & & $P$ & \\
\hline Kowtha and Choon (2001) & E-Commerce & 135 & ADP & PRD & $\mathrm{SRV}$ & MIX & COR & & & & & & & & $\mathrm{P}$ & 0.560 & & & & \\
\hline Kuan and Chau (2001) & EDI & 525 & ADP & PRD & MIX & SML & REG & & & & & & & & & & $\mathrm{P}$ & & $\mathrm{N}$ & \\
\hline Larsen (1998) & IT & 99 & MIX & PRC & MFG & LRG & COR & & & $\mathrm{N}$ & -0.160 & & $\mathrm{~N}$ & 0.210 & & & & & & \\
\hline Law and Ngai (2007) & ERP & 96 & ADP & PRD & MIX & MIX & OTH & & & & & $\mathrm{N}$ & & & & & & & & \\
\hline
\end{tabular}




\begin{tabular}{|c|c|c|c|c|c|c|c|c|c|c|c|c|c|c|c|c|c|c|c|c|}
\hline $\begin{array}{l}\text { Lertwongsatien and } \\
\text { Wongpinunwatana (2003) }\end{array}$ & E-commerce & 386 & ADP & PRD & MIX & SML & OTH & & & & & & & & $P$ & & & & & \\
\hline Looi (2005) & E-Commerce & 184 & ADP & PRD & MIX & SML & COR & & & & & & & & $P$ & 0.620 & P & 0.244 & & \\
\hline Mehrtens et al. (2001) & Internet & 5 & ADP & PRD & $\operatorname{SRV}$ & SML & DES & & & & & & & & & & & & $P$ & \\
\hline $\begin{array}{l}\text { Mirchandani and Motwani } \\
\text { (2001) }\end{array}$ & E-Commerce & 62 & ADP & PRD & MIX & SML & COR & & & & $P$ & 0.570 & & & $\mathrm{~N}$ & 0.048 & & & & \\
\hline \multirow[t]{2}{*}{$\begin{array}{l}\text { Premkumar and } \\
\text { Ramamurthy (1995) }\end{array}$} & $\begin{array}{l}\text { (Inter- } \\
\text { organizational }\end{array}$ & 201 & ADP & MIX & MIX & MIX & COR & & & & & & & & $P$ & 0.023 & & & $P$ & 0.205 \\
\hline & Systems) EDI & 201 & IMP & MIX & MIX & MIX & COR & & & & & & & & $\mathrm{N}$ & 0.110 & & & $\mathrm{~N}$ & 0.088 \\
\hline \multirow{4}{*}{$\begin{array}{l}\text { Premkumar and Roberts } \\
(1999)\end{array}$} & Email & 78 & ADP & PRD & MIX & SML. & DIS & & & & & & & & $P$ & & & & $P$ & \\
\hline & $\begin{array}{l}\text { On-line Data } \\
\text { Access }\end{array}$ & 78 & ADP & PRD & MIX & SML & DIS & & & & & & & & $P$ & & & & $\mathrm{~N}$ & \\
\hline & Internet Access & 78 & ADP & PRD & MIX & SML & DIS & & & & & & & & $\mathrm{N}$ & & & & $P$ & \\
\hline & EDI & 78 & $\mathrm{ADP}$ & PRD & MIX & SML. & DIS & & & & & & & & $P$ & & & & $\mathrm{~N}$ & \\
\hline $\begin{array}{l}\text { Quaddus and Hofmeyer } \\
(2007)\end{array}$ & E-commerce & 211 & INI & PRD & MIX & SML & Отн & $\mathrm{N}$ & & & & & & & $\mathrm{N}$ & & $\mathrm{N}$ & & & \\
\hline \multirow[t]{2}{*}{ Scupola (2003) } & \multirow{2}{*}{ E-commerce } & 7 & ADP & PRD & MIX & SML & DES & & & & & & & & $P$ & & $\mathbf{P}$ & & $P$ & \\
\hline & & 7 & IMP & PRD & MIX & SML. & DES & & & & & & & & $P$ & & $\mathbf{P}$ & & $P$ & \\
\hline Seyal and Rahman (2003) & E-Commerce & 95 & ADP & PRD & MIX & SML & COR & $P$ & 0.350 & & & & & & & & & & & \\
\hline Seyal et al. (2004) & E-Commerce & 54 & ADP & PRD & MIX & SML. & COR & & & & & & & & & & $\mathrm{P}$ & 0.305 & & \\
\hline Seyal et al. $(2007)$ & EDI & so & ADP & PRD & MIX & SML & COR & & & & & & & & & & $\mathbf{P}$ & 0.301 & & \\
\hline Sharma and Rai (2002) & CASE & 350 & ADP & PRD & MIX & MIX & DIS & & & $\mathrm{N}$ & & & & & & & & & & \\
\hline Tang (2000) & Intranet & 190 & ADP & PRD & MIX & MIX & Отн & & & & $\mathrm{P}$ & & & & & & & & & \\
\hline Teo et al. (2009) & E-procurement & 141 & ADP & PRD & MIX & LRG & $\mathrm{COR}$ & & & & & & & & & & & & $\mathrm{P}$ & 0.300 \\
\hline \multirow[t]{2}{*}{ Thong (1999) } & \multirow{2}{*}{ IT } & 294 & ADP & MIX & MIX & SML & COR & & & & $P$ & 0.212 & $\mathrm{P}$ & 0.295 & $\mathrm{~N}$ & -0.091 & & & & \\
\hline & & 294 & IMP & MIX & MIX & SML. & COR & & & & $\mathrm{N}$ & 0.167 & $\mathrm{~N}$ & 0.041 & $\mathrm{~N}$ & -0.056 & & & & \\
\hline Thong and Yap (1995) & $\mathrm{IT}$ & 166 & ADP & MIX & MIX & SML. & COR & $\mathrm{P}$ & 0.311 & & $\mathrm{P}$ & 0.173 & $\mathrm{P}$ & 0.300 & $\mathrm{~N}$ & -0.094 & & & & \\
\hline Tsao et al., (2004) & E-Commerce & 72 & ADP & PRD & MIX & SML & COR & & & & & & & & & & $\mathrm{N}$ & & & \\
\hline \multirow[t]{2}{*}{ Wang and Cheung (2004) } & \multirow{2}{*}{ E-Business } & 137 & ADP & PRD & $\mathrm{SRV}$ & SML. & COR & & & & & & & & $\mathrm{N}$ & 0.270 & & & $\mathrm{~N}$ & 0.180 \\
\hline & & 137 & $\mathrm{IMP}$ & PRD & $\mathrm{SRV}$ & SML. & COR & & & & & & & & $\mathrm{Y}$ & 0.310 & & & $\mathrm{~N}$ & 0.260 \\
\hline
\end{tabular}




\begin{tabular}{|c|c|c|c|c|c|c|c|c|c|c|c|c|c|c|c|c|c|c|c|}
\hline \multirow[t]{2}{*}{ Study } & \multirow[t]{2}{*}{ Innovation } & \multirow{2}{*}{$\begin{array}{l}\text { SAM } \\
\text { SIZE }\end{array}$} & \multirow{2}{*}{$\begin{array}{l}\text { STG } \\
\text { ADP }\end{array}$} & \multirow{2}{*}{$\begin{array}{l}\text { TYP } \\
\text { INO }\end{array}$} & \multirow{2}{*}{$\begin{array}{l}\text { IND } \\
\text { TYP }\end{array}$} & \multirow{2}{*}{$\begin{array}{l}\text { ORG } \\
\text { CAT }\end{array}$} & \multirow[t]{2}{*}{ ANA } & CEO ATT & MNG TEN & \multicolumn{2}{|c|}{ CEO INO } & \multicolumn{2}{|c|}{ CEO KLG } & \multicolumn{2}{|c|}{ COMPRE } & \multicolumn{2}{|c|}{ GOVSUP } & \multicolumn{2}{|c|}{ EXT PRE } \\
\hline & & & & & & & & S CRV & CRV & $s$ & CRV & $\mathrm{s}$ & CRV & $\mathrm{S}$ & CRV & $\mathrm{s}$ & CRV & $\mathbf{S}$ & CRV \\
\hline Zhu et al., (2006a) & E-Business & 1415 & IMP & PRC & MIX & MIX & PLS & & & & & & & $\mathrm{P}$ & & & & & \\
\hline \multirow[t]{3}{*}{ Zhu et al., (2006b) } & & 1857 & INI & PRD & MIX & MIX & COR & & & & & & & $P$ & 0.190 & $P$ & 0.420 & & \\
\hline & E-business & 1857 & $\mathrm{ADP}$ & PRD & MIX & MIX & COR & & & & & & & $P$ & 0.030 & $\mathrm{~N}$ & 0.090 & & \\
\hline & & 1857 & IMP & PRD & MIX & MIX & COR & & & & & & & $\mathrm{P}$ & 0.010 & $\mathbf{P}$ & 0.150 & & \\
\hline
\end{tabular}

Stage of Adoption - S TG ADP, Initiation - INL Adoption - ADP, mplementation - IMP, Mixed - MIX S ample Sire - SAMS EE Type of hnovation - TYP INO, Product - PRD, Process - PRC, Mixed - MD Organkation Category- ORG CAT, Larg - LRG, S mal-S ML., Mixed - MD hdustry Type - ND TYP, Manufacturing - MFG, S ervice - S RV, Mixed - MIX

Analysis-ANA, Correlation - COR, Regression - REG, Dicriminant- DS, Descriptive - DES, PLS - PLS, Other- OTH

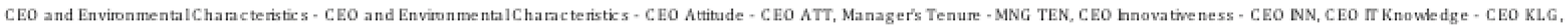
Competitive Pressure - COMPRE, G ove mmentS uppot-GOV SUP, ExtemalPressure - EXTPRE

S-Significance: $S$ ignificant- P, Notsignifix ant - N, CRV - Comrbtionvalues 